\title{
The enhancement of electrochemical capacitance of biomass-carbon by pyrolysis of extracted nanofibers
}

DOI:

10.1016/j.electacta.2017.01.099

\section{Document Version}

Accepted author manuscript

Link to publication record in Manchester Research Explorer

\section{Citation for published version (APA):}

Deng, L., Zhong, W., Wang, J., Zhang, P., Fang, H., Yao, L., Liu, X., Ren, X., \& Li, Y. (2017). The enhancement of electrochemical capacitance of biomass-carbon by pyrolysis of extracted nanofibers. Electrochimica Acta, 20. https://doi.org/10.1016/j.electacta.2017.01.099

\section{Published in:}

Electrochimica Acta

\section{Citing this paper}

Please note that where the full-text provided on Manchester Research Explorer is the Author Accepted Manuscript or Proof version this may differ from the final Published version. If citing, it is advised that you check and use the publisher's definitive version.

\section{General rights}

Copyright and moral rights for the publications made accessible in the Research Explorer are retained by the authors and/or other copyright owners and it is a condition of accessing publications that users recognise and abide by the legal requirements associated with these rights.

\section{Takedown policy}

If you believe that this document breaches copyright please refer to the University of Manchester's Takedown Procedures [http://man.ac.uk/04Y6Bo] or contact uml.scholarlycommunications@manchester.ac.uk providing relevant details, so we can investigate your claim.

\section{OPEN ACCESS}




\section{Accepted Manuscript}

Title: The enhancement of electrochemical capacitance of biomass-carbon by pyrolysis of extracted nanofibers

Authors: Libo Deng, Wenhua Zhong, Jubei Wang, Peixin Zhang, Haoming Fang, Lei Yao, Xuqing Liu, Xiangzhong Ren, Yongliang Li

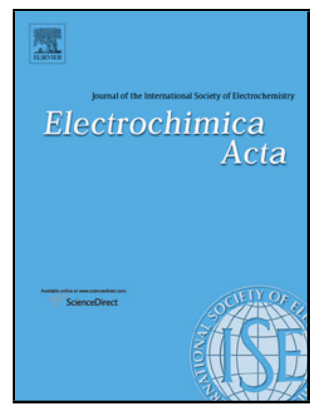

PII: S0013-4686(17)30125-1

DOI: http://dx.doi.org/doi:10.1016/j.electacta.2017.01.099

Reference: EA 28766

To appear in: $\quad$ Electrochimica Acta

Received date: $\quad$ 20-11-2016

Revised date: $\quad 18-12-2016$

Accepted date: $\quad 17-1-2017$

Please cite this article as: Libo Deng, Wenhua Zhong, Jubei Wang, Peixin Zhang, Haoming Fang, Lei Yao, Xuqing Liu, Xiangzhong Ren, Yongliang Li, The enhancement of electrochemical capacitance of biomass-carbon by pyrolysis of extracted nanofibers, Electrochimica Acta http://dx.doi.org/10.1016/j.electacta.2017.01.099

This is a PDF file of an unedited manuscript that has been accepted for publication. As a service to our customers we are providing this early version of the manuscript. The manuscript will undergo copyediting, typesetting, and review of the resulting proof before it is published in its final form. Please note that during the production process errors may be discovered which could affect the content, and all legal disclaimers that apply to the journal pertain. 


\section{The enhancement of electrochemical capacitance of biomass-carbon by pyrolysis of extracted nanofibers}

Libo Deng ${ }^{\mathrm{a}}$, Wenhua Zhong ${ }^{\mathrm{a}}$, Jubei Wang ${ }^{\mathrm{a}}$, Peixin Zhang ${ }^{\mathrm{a}}$, Haoming Fang ${ }^{\mathrm{b}}$, Lei Yao ${ }^{\mathrm{a}}$, Xuqing Liu ${ }^{\mathrm{c}}$, Xiangzhong Ren ${ }^{\mathrm{a}}$, and Yongliang $\mathrm{Li}^{\mathrm{a}}$

${ }^{\mathrm{a} C o l l e g e}$ of Chemistry and Environmental Engineering, Shenzhen University, Shenzhen 518060, China

${ }^{b}$ Department of Materials Science and Engineering, CAPT/HEDPS/LTCS, Key Laboratory of Polymer Chemistry and Physics of Ministry of Education, College of Engineering, Peking University, Beijing 100871, China

${ }^{\mathrm{c} S}$ School of Materials, University of Manchester, Oxford Road, M13 9PL, UK

* Corresponding author: pxzhang@szu.edu.cn; Tel: +86-755-26536157

\section{Graphical abstract}

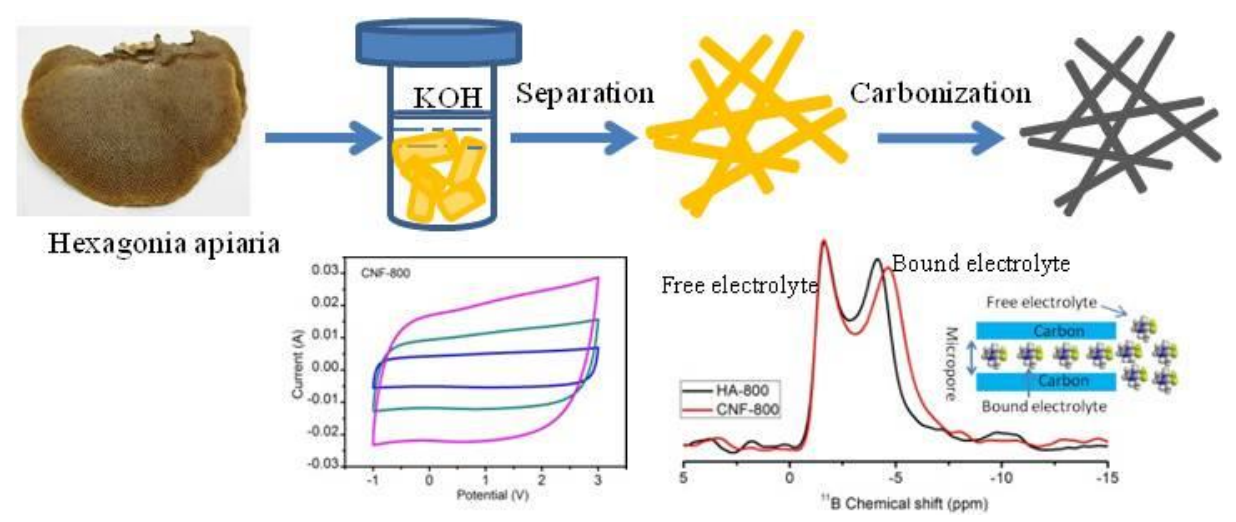




\begin{abstract}
Biomass-derived carbons have been extensively researched as electrode material for energy storage and conversion recently. However, most of the previous works convert crude biomass directly into carbon and the electrochemical capacitances for the resultant carbons are quite often underestimated as well as large variations in capacitances exist in literatures due to the complex nature of biomass, which practically hinder their applications. In this work, polysaccharide nanofibers were extracted from an inexpensive natural fungus using a hydrothermal method and were converted to porous carbon nanofibers (CNFs) by potassium hydroxide activation. The porous carbons were assembled into symmetric supercapacitors using both potassium hydroxide and an ionic liquid (IL) as electrolytes. Solid state nuclear magnetic resonance characterization showed that the micropores of the as-prepared carbons are accessible to the IL electrolyte when uncharged and thus high capacitance is expected. It is found in both electrolytes the electrochemical capacitances of CNFs are significantly higher than those of the porous carbon derived directly from the crude fungus. Furthermore, the CNFs delivered an extraordinary energy density of 92.3 $\mathrm{Wh} \mathrm{kg}^{-1}$ in the IL electrolyte, making it a promising candidate for electrode materials for supercapacitors.
\end{abstract}

Keywords: Supercapacitors; Extraction of biomass; nuclear magnetic resonance 


\section{Introduction}

Carbon is currently the dominating electrode material for commercial supercapacitors due to its high electrical conductivity, low cost and long cycling life [1]. Among the various types of carbon-based electrode material such as activated carbons, graphene and carbon nanotubes, porous carbons derived from biomass are particularly promising due to the abundance, low cost and the hierarchical structures of the raw materials $[2,3]$. High electrochemical capacitances have been achieved with carbons derived from a variety of biomass such as lotus, watermelon, leaves, and hemp fibers [4-10]. However, most of the work converted crude biomass directly into carbon; there are large variations in the capacitances for biomass-derived carbons in literatures. This might be due to the heterogeneous structure for the precursor and the overheating and condensation of the skeleton during carbonization as biomass are typically complex mixtures of biopolymers and inorganic salts. The carbonization behavior, structure and performance of the carbon derived from each individual component such as cellulose, hemicellulose and lignin, can be significantly different from those for the crude biomass [11]. Removing the shielding component from the crude biomass might promote the conversion of polysaccharide into carbon [12]. Recently, Jiang et al demonstrated that in bamboo chopsticks, cellulose fibers can be separated from the lignin and hemicelluloses matrices through a facile hydrothermal method, and the carbon derived from the separated fibers shows a higher surface area and higher capacity than those of the bulk bamboo-derived carbon as an anode material for Li-ion battery [13]. Similar enhancement in the capacitance of corn 
cob-derived carbon has also been observed by removing the lignin and carbonizing the crystalline cellulose only [14]. It is proposed that carbonizing the components separately instead of the whole biomass might increase the surface area and improve the uniformity of the derived carbon, which are crucial for practical applications.

In our previous study, an industrial biopolymer cellulose was used as the precursor to prepare carbon nanofibers and homogeneous structure across the carbon monolith and good capacitive performance was achieved [15]. We also demonstrated that hexagonia apiaria (HA) which is an inexpensive fungus composed of mainly dextrin, can be converted into porous carbons which would exhibit excellent electrocatalytic activity when doped with nitrogen and sulfur [16]. In the present study, the nanofibrils in HA were extracted from the bulk prior to the carbonization process. It was found that carbons derived from the extracted fibers possess a higher surface area and enhanced electrochemical capacitance in both aqueous and ionic liquid (IL) electrolytes than those derived directly from the crude HA.

\section{Experimental}

\subsection{Materials}

Hexagonia apiaria was collected from Nanshan lychee orchard, Shenzhen. Potassium hydroxide $(\mathrm{KOH})$, Polytetrafluoroethylene $(60 \% \mathrm{w})$, and an ionic liquid 1-Ethyl-3- Methylimidazolium Tetrafluoroborate $\left(\mathrm{EMIImBF}_{4}\right)$ were purchased from Aladdin Chemicals. Sulfuric acid (98\%) was purchased from Guanghua Chemicals. All the chemicals were analytic grade and used without further purification. 


\subsection{Preparation of porous activated carbon}

The HA fungus was washed and cleaned by water and dried in an oven at $60^{\circ} \mathrm{C}$, which was then cut into chips with a length of $\sim 1.5 \mathrm{~cm}$ and a width of $\sim 0.5 \mathrm{~cm}$. To extract the nanofibers from HA, $2 \mathrm{~g}$ of the chips were put into a stainless steel autoclave with Teflon-lined while adding $70 \mathrm{ml}$ of $3 \mathrm{M} \mathrm{KOH}$ solution and treated at $150^{\circ} \mathrm{C}$ for $6 \mathrm{~h}$. The cooled solution was then neutralized with sulfuric acid, and the precipitate was collected by filtration and rinsed thoroughly. The preparation procedure is shown in Figure 1.

\section{Figure 1.}

To prepare porous carbon, both the crude HA and extracted nanofibers were mixed with $\mathrm{KOH}$ with a mass ratio of $1: 3$. The mixtures were then treated at $800{ }^{\circ} \mathrm{C}$ in a nitrogen atmosphere for $2 \mathrm{~h}$, with a ramp rate of $10{ }^{\circ} \mathrm{C} \mathrm{min}^{-1}$. The residues were then thoroughly washed with sulfuric acid and deionized water. The resultant carbons were denoted as HA-800 and CNF-800, respectively.

\subsection{Characterization}

Scanning electron microscopy (SEM) investigation was performed on a Navo Nano 450 microscope. Microstructures of the active carbons were investigated using a JEOL JEM-2100 transmission electron microscope (TEM). Raman spectra were obtained using a Horiba LabRAM HR800 spectrometer coupled to a $633 \mathrm{~nm}$ laser. The crystal structure of the fibers was examined using a Philips X'PERT APD powder $\mathrm{X}$-ray diffractometer (XRD, $\lambda=1.54 \AA, \mathrm{CuK} \alpha$ radiation). The specific surface area 
and pore size distribution of the carbon materials were characterized using nitrogen adsorption at $77 \mathrm{~K}$ (Micrometrics ASAP 2020). Thermogravitermic (TG) analysis of the precursors was carried out using a Jupiter Netzsch STA 449 C instrument. Fourier transform infrared (FTIR) spectra were collected using a Nicolet 6700 spectrometer. X-ray photoelectron spectroscopy (XPS) measurements were performed on an Ultra DLD using a monochromic Al X-ray source. Solid state nuclear magnetic resonance (NMR) experiments were performed using a Bruker Avance III HD 400 spectrometer equipped with $2.5 \mathrm{~mm}$ double-resonance MAS probes, and the rotor was spinning at 10,000 rpm. To prepare the NMR samples, porous carbons were degassed at $150{ }^{\circ} \mathrm{C}$ for $3 \mathrm{~h}$ under vacuum and $0.1 \mathrm{~g}$ of the degassed carbon was soaked into $0.2 \mathrm{~g}$ of an acetonitrile solution of the $\mathrm{IL} \mathrm{EMIImBF}_{4}(\mathrm{wt} .50 \%)$ for $30 \mathrm{~min}$, and the solvent was then removed in a vacuum oven at room temperature.

\subsection{Capacitance measurement}

Supercapacitors were constructed following the procedure described in our previous study [15]. Specifically, $80 \mathrm{mg}$ of the porous carbons was ground and mixed with $10 \mathrm{mg}$ of carbon black and an aqueous suspension of PTFE (10 mg). The paste was then casted onto nickel foam, dried under vacuum at $50{ }^{\circ} \mathrm{C}$ for $24 \mathrm{~h}$ and pressed to give the electrodes. Supercapacitors were built by assembling two pieces of the electrode, with a filter paper as a separator in a coin cell. Two types of electrolyte were used to assemble supercapacitors, i.e. $6 \mathrm{M}$ aqueous $\mathrm{KOH}$ and $\mathrm{EMIImBF}_{4}$. The loading of carbons in each electrode was $5 \mathrm{mg}$. The performance was then tested using cyclic voltammetry (CV) and galvanostatic charge/discharge (GCD) methods. 
The specific capacitance $C_{\mathrm{sp}}$ for each electrode was determined using Eqn (1) [17]: $C_{\mathrm{sp}}=4 \times I \times t /(m \times \Delta V)$ where $I$ is the current, $\Delta V$ is the potential change within the discharge time, $t$ is the discharge time, and $m$ is the total mass of active materials in both electrodes. The energy density was calculated using Eqn (2): $E_{\mathrm{t}}=0.5 \times C_{\mathrm{t}} \times(\Delta V)^{2}$ and the power density was calculated using Eqn (3): $P_{\mathrm{t}}=E_{\mathrm{t}} / t$ where $E_{\mathrm{t}}$ is the energy density, $P_{\mathrm{t}}$ is the power density, and $C_{\mathrm{t}}$ is the specific capacitance of the total device. The cyclic stability tests were carried out using a CT2001A battery tester and all other electrochemical measurements were performed on a CHI760E electrochemical workstation.

\section{Results and discussion}

\subsection{Structural characterization}

The crude HA was first treated through a $\mathrm{KOH}$ hydrothermal process, during which the major composition dextran underwent hydrolysis and the nanofibers formed stable dispersion in the $\mathrm{KOH}$ solution due possibly to the electrostatic repulsion. The suspension was neutralized and the nanofibers precipitated out of the solution which were then collected and rinsed thoroughly. SEM observation into the crude HA-derived carbon reveals networks of hollow carbon fibers (Figure 2a). After hydrothermal treatment of the crude $\mathrm{HA}$ in $\mathrm{KOH}$ solution, polysaccharide nanofibers were extracted which were further converted into porous carbon. Figure $2 b$ shows the SEM image of the carbon nanofibers which were carbonization product of the extracted nanofibers. It can be seen that the product retained the fibrous morphology 
and are well separated from each other. The average diameter decreased from $2 \mu \mathrm{m}$ for the hollow fibers in crude HA-derived carbon to $620 \mathrm{~nm}$ for the carbon nanofibers (CNFs). The smaller diameter of the nanofiber precursor than the crude HA might lead to a higher surface area for the resultant carbon. Our previous study demonstrated that during carbonization, a higher degree of graphitization and more uniform structure can be obtained when a nano-sized precursor is used as compared to the micro-scale precursor [18]. TEM inspection into the porous carbons indicate a slightly higher degree of graphitization in the CNF than in the crude HA-derived carbon, as can be seen from Figures $2 \mathrm{c}$ and $2 \mathrm{~d}$.

\section{Figure 2.}

The chemical structures of the crude HA and the extracted nanofibers were characterized using infrared spectroscopy and the spectra are shown in Figure 3a. The peaks at $3419 \mathrm{~cm}^{-1}, 2923 \mathrm{~cm}^{-1}$ and $1373 \mathrm{~cm}^{-1}$ correspond to the stretching of $\mathrm{OH}$, stretching and bending of $\mathrm{CH}$, respectively, suggesting the dominating polysaccharide composition of HA. The $\mathrm{OH}$ peak at $~ 3400 \mathrm{~cm}^{-1}$ in the extracted nanofibers is reduced significantly upon hydrothermal and acidification treatments, which indicates the hydrolysis of the polysaccharide. The TG and differential thermogravimetric (DTG) curves of the raw HA and extracted nanofibers are shown in Figure $3 \mathrm{~b}$. It can be seen the weight loss occurs at a much slower rate and in a wider temperature range for the extracted nanofibers than for the crude HA during carbonization. It was demonstrated in our previous study that the chemical reactions involved in the $240{ }^{\circ} \mathrm{C}-400{ }^{\circ} \mathrm{C}$ range 
influence the microstructure of the resultant carbon significantly [18]. The slower reaction for the extracted nanofibers would allow a more complete rearrangement of carbon atoms and eventually lead to a higher structural order in the nanofiber-derived carbon which was confirmed by XRD and Raman characterizations. Both the crude $\mathrm{HA}$ and extracted nanofibers were carbonized and activated at $800^{\circ} \mathrm{C}$ and the crystallite structure was characterized using XRD (Figure 3c). The broad peak at around $23.4^{\circ}$ suggest amorphous nature for both HA-800 and CNF-800. Compared with HA-800, the peak for CNF-800 is narrower and more intense, which indicates a higher structural order for the latter.

The structure was further characterized by Raman spectroscopy (Figure 3d). It can be seen that the intensity ratio between the $\mathrm{D}$ band and the $\mathrm{G}$ band, $I_{\mathrm{D}} / I_{\mathrm{G}}$, increases from 1.4 for HA-800 to 1.55 for CNF-800. Previous studies demonstrated that a higher $I_{\mathrm{D}} / I_{\mathrm{G}}$ corresponds to a larger graphitic domain for small crystallites $[19,20]$. Thus the Raman characterization suggests a higher graphitization degree for CNF-800, which is in accordance with the XRD results. Furthermore, the standard deviation of $I_{\mathrm{D}} / I_{\mathrm{G}}$ ratio was 0.18 and 0.12 for HA-800 and CNF-800, respectively, which suggests that the latter carbon possess a more uniform structure than the former due possibly to the more uniform carbonization condition inside the precursor.

The surface area of the porous carbon was measured using a nitrogen adsorption/desorption method and the $\mathrm{N}_{2}$ adsorption-desorption isothermal cures are shown in Figures 3e. Both HA-800 and CNF-800 exhibit a typical "type I" characteristic, and the specific surface area increased from $895 \mathrm{~m}^{2} \mathrm{~g}^{-1}$ for HA-800 to 
$1280 \mathrm{~m}^{2} \mathrm{~g}^{-1}$ for CNF-800. The micropores account for $45 \%$ and $49 \%$ and the mesopores account for $55 \%$ and $51 \%$ of the total surface areas for HA-800 and CNF-800, respectively. The average diameter estimated using the Barrett-Joyner-Halenda method (BJH) model for CNF-800 is $2.2 \mathrm{~nm}$ and that for HA-800 is $2.8 \mathrm{~nm}$. Such pore size distributions (shown as inset in Figure 3e) and the small average diameter for these carbons are beneficial for the ion storage based on electrostatic adsorption. The concentration of the elements on the surface were further analyzed by XPS and the full spectra are shown in Figure 3f. The molar fractions of carbon, nitrogen and oxygen were $93.09 \%, 1.91 \%$ and $5 \%$ in HA-800 and $95.26 \%$, $1.37 \%$ and $3.37 \%$ in CNF-800, respectively. The slightly lower contents of heteroatoms in CNF-800 did not result in a lower capacitance compared to HA-800, due to the dominating electrical double layer capacitance which will be discussed later.

\section{Figure 3.}

For energy storage based on electrical double layer capacitance, it is crucial that the internal surfaces of the electrode materials are accessible to ions. The accessibility of the micropores of the as-prepared carbons to electrolytes was investigated using NMR spectroscopy, which is achieved by analysising the perturbation of NMR spectra of the electrolyte induced by the adsorbents. When the electrolytes are confined in a nanopore, the NMR peak for a nucleus shifts to a higher position due to the diamagnetic shielding effect of the $\mathrm{sp}^{2}$ hybridized carbon networks [21]. Such effect is 
only appreciable when the pores are small enough (i.e. micropores) and thus the NMR technique can be used to probe the infiltration of ions into small pores [21-24]. Both HA-800 and CNF-800 were impregnated with an acetonitrile solution of EMIImBF 4 and ${ }^{11} \mathrm{~B}$ NMR spectra were acquired for the electrolyte-loaded carbons after evaporating the solvent and the results are shown in Figure 4. For both samples, the ${ }^{11} \mathrm{~B}$ peak split into two components. The one at $-1.4 \mathrm{ppm}$ corresponds to free electrolyte molecules (or weakly bound electrolytes) whereas the one at higher position are ascribed to the strongly bound electrolytes in micropores or small mesopores. The shift of the ${ }^{11} \mathrm{~B}$ peak upon adsorption of the electrolyte for HA-800 relative to the free molecules was $2.6 \mathrm{ppm}$ whereas this value was $3 \mathrm{ppm}$ for $\mathrm{CNF}-800$, i.e. a stronger interaction between the electrolyte and the carbon surface in the latter sample due to a smaller average pore size and higher graphitization degree. This result also suggests that the electrolyte can wet the carbons and infiltrate into the small pores (particularly the micropores) when uncharged, and the stronger interaction in CNF-800 indicates an enhanced wettability which is the prerequisite for efficient energy storage. Furthermore, the slightly higher intensity of the peak for the bound electrolyte suggests a higher fraction of electrolytes adsorbed in the small pores of HA-800 than in those of CNF-800. The fraction of the strongly adsorbed electrolytes accounted for $\sim 69 \%$ of the total electrolytes for CNF-800 while this value was $65 \%$ for HA-800, both estimated using the peak areas. These results suggest the adsorption of electrolytes is critically determined by the pore structure. However, the kinetics for penetration of ions into the pores and the arrangement of electrical double layer (e.g. 
whether desolvation and distortion of the ions occur or not) upon charging remains our future work.

\section{Figure 4.}

\subsection{Electrochemical performance in aqueous $\mathrm{KOH}$ electrolyte}

A three-electrode configuration was first used to investigate the electrochemistry of the porous carbons and the $\mathrm{CV}$ curves are shown in Figure 5. Both samples displayed rectangular-like $\mathrm{CV}$ curves with only slight distortions, and no obvious redox peaks were observed, which confirms that the main contribution for the energy storage in these carbons is from electrical double layer capacitance.

\section{Figure 5.}

The capacitive performance of the porous carbons was investigated by assembling the electrodes into symmetric supercapacitors using a $\mathrm{KOH}$ aqueous solution as the electrolyte. CV curves obtained at different scan rates for CNF-800 are shown in Figure 6a. Typical rectangular shape without any redox peak is seen for the curves, again suggesting electrical double layer nature of the energy stored in the porous carbon which provides a route for reversible adsorption and desorption of ions. HA-800 showed similar CV responses, although with lower currents. The capacitance was further determined by GCD measurements and typical curves are shown in Figure 6b. The capacitance measured at a current density of $1 \mathrm{~A} \mathrm{~g}^{-1}$ for CNF-800 was $324 \mathrm{~F}$ $\mathrm{g}^{-1}$, which is over twice of the values measured for HA-800 $\left(155 \mathrm{~F} \mathrm{~g}^{-1}\right)$. A comparison with the literature data (Table 1) on electrochemical capacitance of biomass-derived 
carbon suggests that the CNF-800 is superior to most of the good results obtained by pyrolysising crude biomass such as willow catkin and tobacco rods [25-30]. Furthermore, the high capacitance of CNF-800 was achieved at a moderate specific surface area compared to other biomass-derived carbons, which is evident from the areal capacitance (i.e. normalized to the surface area) listed in Table 1. A relatively low surface area is beneficial for practical application as a higher surface area would adsorb more electrolytes and reduce the gravimetric capacitance of the device. It is recognized that the charge storage based on an electrical double layer mechanism for a material does not only depend on the surface area; the electrical conductivity, wettability and pore size distribution also influence the capacitive performance significantly. The extraordinary area capacitance of CNF-800 could be related to the suitable pore size and excellent wettability as revealed by the NMR analysis. It should be noted, however, large variations in capacitance of biomass-carbon appear in literatures and strict comparison is difficult to make due to the different testing configurations (i.e. three- or two-electrode) and conditions (i.e. the discharging rate). Nevertheless, this work utilizes the same activation method for preparation and the same conditions for testing the performance of HA-800 and CNF-800, which clearly demonstrated that the performance of biomass-carbon can be enhanced by separating the components from the biomass prior to carbonization. Such enhancement is thought to be attributed to a higher structural order, larger surface areas and better wettability in the CNFs than in the crude-HA-derived carbon.

\section{Table 1}


The rate performance was evaluated up to a current density of $20 \mathrm{~A} \mathrm{~g}^{-1}$ (Figure 6c). As is expected the capacitance decreased with the increasing current density due to that the ions movement is limited only to the surfaces of the electrode material at a higher current density [31], and the rate performance can be improved by optimizing the pore size distribution of the carbons. It can be seen for CNF-800, the capacitance measured at $20 \mathrm{~A} \mathrm{~g}^{-1}$ still retained $79 \%$ of its value measured at $0.5 \mathrm{~A} \mathrm{~g}^{-1}$. The capacitance of HA-800 decreased faster with the increase of discharge current, retaining $70 \%$ of the value measured at $0.5 \mathrm{~A} \mathrm{~g}^{-1}$. The cyclic performance of the electrode was also assessed by repetitive charge/discharge tests of the supercapacitors at a current density of $2 \mathrm{~A} \mathrm{~g}^{-1}$ for 5000 cycles (Figure 6d). The capacitance drops relatively fast during the first few charging cycles due to ion trapping or surface reactions [32]. After about 400 cycles, both HA-800 and CNF-800 were stabilized and the final reduction of capacity after 5000 cycles was $\sim 6.6 \%$ and $\sim 3.7 \%$, respectively. It is thought that the graphitic structure which is a denser stacking of carbon layers is favored over the amorphous carbon for rate and cyclic performances. A more uniform structure is also beneficial for the cycle life of the electrode.

\section{Figure 6.}

Electrochemical impedance spectroscopy (EIS) was carried out in the frequency range of $0.1 \mathrm{~Hz}-100 \mathrm{kHz}$ to further investigate the behavior of the electrodes. Figure 7 shows the Nyquist plots of all electrodes. The nearly vertical straight line paralle to Z" 
axis in the low frequency region indicates capacitive nature of these carbon materials. In the high frequency region, the semicircle is related to properties of electrode such as porosity, conductive, thickness of electrode as well as the difussion of ions. The equivalent circuit used for the impedance analysis, which is a combination of capacitor and resistors to reflect the real double layer capacitance and the resistance of electrolyte ion diffusion into porous carbon materials, is also shown in Figure 7 [33]. The solution resistance $\left(R_{\mathrm{S}}\right)$ and the charge transfer resistance $\left(R_{\mathrm{ct}}\right)$ of the electrodes can be determined from the intercept at the real axis $\left(\mathrm{Z}^{\prime}\right)$ and the diameter of the semicircle, which is $0.45 \Omega$ and $0.5 \Omega$ for CNF-800, respectively. These values are $0.82 \Omega$ and $0.54 \Omega$ for HA-800, respectively. This suggests a lower resistance for CNF-800 than HA-800, which can be explained by a higher graphitization degree and higher surface area accessble to the electrolyte for the former carbon.

\section{Figure 7.}

\subsection{Electrochemical performance in the IL electrolyte}

Electrolytes with wider electrochemical window are more favorable compared to the aqueous electrolytes as the energy density of a supercapacitor scales with the square of voltage according to Eqn (2). Room temperature ILs are promising electrolyte alternative to aqueous electrolytes due to their higher operating voltage and the lower vapor pressure $[34,35]$. Therefore, the electrochemical performance of the as-prepared porous carbons in the IL EMIImBF 4 was also tested. The CV curves measured in the range of -1 to $3 \mathrm{~V}$ for CNF-800 are shown in Figure $8 \mathrm{a}$. It can be seen 
the curves are nearly rectangular at low scan rates but distortion is observed when the scan rate is increased to $100 \mathrm{mV} \mathrm{s}^{-1}$. In addition, GCD curves showed linear behavior at low current densities (Figure 8b). The voltage drop becomes obvious when the current density exceeds $10 \mathrm{~A} \mathrm{~g}^{-1}$ for both HA-800 and CNF-800. EIS measurements showed that the $R_{\mathrm{S}}$ is $4.2 \Omega$ and $2.5 \Omega$ for HA-800 and CNF- 800 , while the $R_{\mathrm{ct}}$ is $3.2 \Omega$ and $1.7 \Omega$, respectively, suggesting improved electrical conductivity in the exfoliated nanofiber electrode. The higher resistances in the IL electrolytes than in the aqueous electrolyte for both systems revealed by EIS are also consistent with the CV and GCD measurements.

The rectangular shape for the CV curves and the linear GCD curves again suggest typical electrical double layer capacitive characteristic in the IL electrolyte. The CNF-800 showed a specific capacitance of $171 \mathrm{~F} \mathrm{~g} \mathrm{~g}^{-1}$ at a current density of $1 \mathrm{~A} \mathrm{~g}^{-1}$, which is $70 \%$ higher than that of HA-800. As the current density increased to $20 \mathrm{~A} \mathrm{~g}^{-1}$, the CNF-800 retained $72 \%$ of the capacitance measured at $0.5 \mathrm{~A} \mathrm{~g}^{-1}$ whereas the retention for HA-800 was $69 \%$ (Figure 8c). These results indicate that the capacitances for both porous carbons in the IL electrolyte are lower than in aqueous electrolytes, and the decay of capacitance at higher discharge current is even more severe, although the rate performance for the two carbons in our case is already better than good results in literatures for carbon materials in IL electrolytes such as carbon nanofibers [36] and heteroatom-doped-graphene in IL [37]. The lower capacitance and the deteriorate rate performance in IL than in the $\mathrm{KOH}$ are attributed to the relative difference between pore size in the electrode and size of the ions in the electrolyte [31]. The durability of the supercapacitors containing the IL electrolyte was also examined. The HA-800 retained $95.2 \%$ of its initial capacitance whereas the retention for CNF-800 was $96.8 \%$, similar to their cyclic performances in the $\mathrm{KOH}$ electrolyte. 
Despite the lower capacitances in the IL electrolyte, both HA-800 and CNF-800 showed significantly higher energy densities than in aqueous electrolyte due to the larger voltage window. Specifically, the CNF-800 showed an extraordinary energy density of $92 \mathrm{Wh} \mathrm{kg}^{-1}$ at a power density of $493 \mathrm{~W} \mathrm{~kg}^{-1}$ and it still retains a value of $35 \mathrm{Wh} \mathrm{kg}^{-1}$ at $14 \mathrm{~kW} \mathrm{~kg}^{-1}$, as can be seen from the Ragone plot shown in Figure 8d. It is noteworthy that CNF-800 also shows an energy density of $11.3 \mathrm{Wh} \mathrm{kg}^{-1}$ at $60 \mathrm{~W}$ $\mathrm{kg}^{-1}$ in the aqueous electrolyte due to the impressive capacitance. The energy densities shown here are superior to the commercial carbon-based supercapacitors $\left(<3 \mathrm{Wh} \mathrm{kg}^{-1}\right)$, and are higher than or comparable to other biomass-derived carbons for both aqueousand IL-based supercapacitors (Table 1). Moreover, the performance of the IL-based supercapacitor is even comparable to those obtained with hybrid batteries based on metal and metal oxides (60 100 $\left.\mathrm{Wh} \mathrm{kg}^{-1}\right)$ [38, 39]. The extraordinary energy densities for our porous carbons are attributed to the higher voltage window than those used in previous works [4, 40-42]. It is thus clearly demonstrated that nanofibers extracted from HA fungus is a promising carbon source for high-performance electrode material for supercapacitors. These results also manifest that the performance of a carbon derived from a single component separated from the biomass can be substantially higher than that derived from the whole biomass which is complex mixture of organic and inorganic compounds.

\section{Figure 8.}




\section{Conclusions}

Polysaccharide nanofibers were extracted from HA through a hydrothermal method. Porous carbons derived from the extracted nanofibers exhibited a two-fold increase in electrochemical capacitance than those derived directly from the crude HA tested in $\mathrm{KOH}$ aqueous solution, which is due to the larger surface area and a higher structural order. TGA characterization indicated that structural difference is related to a slower and more complete rearrangement of carbon atoms during the carbonization process. The structural feature exerts the nanofiber-derived carbon with stronger interaction with the electrolyte than the crude HA-derived carbon as disclosed by NMR characterization. Porous carbon derived from both precursors also showed high energy densities in an IL electrolyte. The results demonstrated in this study paves the way for efficient utilization of biomass for applications in electrochemical energy storage.

\section{Acknowledgements}

This work was supported by the National Natural Science Foundation of China (51374146, 51602202 and 21671136), Shenzhen Government's Plan of Science and Technology (JCYJ20150324141711596 and JCYJ20160422112012739), and the Natural Science Foundation of Guangdong (2015A030310087, 2015A030313542 and 2016A030313057). 


\section{References}

1. T. Lin, I.-W. Chen, F. Liu, C. Yang, H. Bi, F. Xu, F. Huang, Nitrogen-doped mesoporous carbon of extraordinary capacitance for electrochemical energy storage, Science 350 (2015) 1508-1513.

2. S. Dutta, A. Bhaumik, K.C.W. Wu, Hierarchically porous carbon derived from polymers and biomass: effect of interconnected pores on energy applications, Energy Environ. Sci. 7 (2014) 3574-3592.

3. L. Zhang, Z. Liu, G. Cui, L. Chen, Biomass-derived materials for electrochemical energy storages, Prog. Polym. Sci. 43 (2015) 136-164.

4. H. Wang, Z. Xu, A. Kohandehghan, Z. Li, K. Cui, X. Tan, T.r.J. Stephenson, C.K. King'ondu, C.M.B. Holt, B.C. Olsen, J.K. Tak, D. Harfield, A.O. Anyia, D. Mitlin, Interconnected Carbon Nanosheets Derived from Hemp for Ultrafast Supercapacitors with High Energy, ACS Nano 7 (2013) 5131-5141.

5. X.-L. Wu, T. Wen, H.-L. Guo, S. Yang, X. Wang, A.-W. Xu, Biomass-Derived Sponge-like Carbonaceous Hydrogels and Aerogels for Supercapacitors, ACS Nano 7 (2013) 3589-3597

6. B. Liu, X. Zhou, H. Chen, Y. Liu, H. Li, Promising porous carbons derived from lotus seedpods with outstanding supercapacitance performance, Electrochim. Acta 208 (2016) 55-63.

7. I.I. Misnon, N.K.M. Zain, R.A. Aziz, B. Vidyadharan, R. Jose, Electrochemical properties of carbon from oil palm kernel shell for high performance supercapacitors, Electrochim. Acta 174 (2015) 78-86.

8. C. Peng, X.-b. Yan, R.-t. Wang, J.-w. Lang, Y.-j. Ou, Q.-j. Xue, Promising activated carbons derived from waste tea-leaves and their application in high performance supercapacitors electrodes, Electrochim. Acta 87 (2013) 401-408.

9. M. Biswal, A. Banerjee, M. Deo, S. Ogale, From dead leaves to high energy density supercapacitors, Energ Environ. Sci. 6 (2013) 1249-1259.

10. Z. Li, Z. Xu, X. Tan, H. Wang, C.M.B. Holt, T. Stephenson, B.C. Olsen, D. Mitlin, 
Mesoporous nitrogen-rich carbons derived from protein for ultra-high capacity battery anodes and supercapacitors, Energ Environ. Sci. 6 (2013) 871-878.

11. J. Deng, T. Xiong, H. Wang, A. Zheng, Y. Wang, Effects of Cellulose, Hemicellulose, and Lignin on the Structure and Morphology of Porous Carbons, ACS Sustainable Chem. Eng. 4 (2016) 3750-3756.

12. F. Liu, M. Guo, Comparison of the characteristics of hydrothermal carbons derived from holocellulose and crude biomass, J. Mater. Sci. 50 (2015) 1624-1631.

13. J. Jiang, J. Zhu, W. Ai, Z. Fan, X. Shen, C. Zou, J. Liu, H. Zhang, T. Yu, Evolution of disposable bamboo chopsticks into uniform carbon fibers: a smart strategy to fabricate sustainable anodes for Li-ion batteries, Energy Environ. Sci. 7 (2014) 2670-2679.

14. M. Genovese, J.H. Jiang, K. Lian, N. Holm, High capacitive performance of exfoliated biochar nanosheets from biomass waste corn cob, J. Mater. Chem. A 3 (2015) 2903-2913.

15. L. Deng, R.J. Young, I.A. Kinloch, A.M. Abdelkader, S.M. Holmes, D.A. De Haro-Del Rio, S.J. Eichhorn, Supercapacitance from cellulose and carbon nanotube nanocomposite fibers, ACS Appl. Mater. Interfaces 5 (2013) 9983-9990.

16. L. Deng, H. Fang, P. Zhang, A. Abdelkader, X. Ren, Y. Li, N. Xie, Nitrogen and sulfur dual-doped carbon microtubes with enhanced performances for oxygen reduction reaction, J. Electrochem. Soc. 163 (2016) H343-H349.

17. M.D. Stoller, R.S. Ruoff, Best practice methods for determining an electrode material's performance for ultracapacitors, Energ Environ. Sci. 3 (2010) 1294-1301.

18. L. Deng, R.J. Young, I.A. Kinloch, Y.Q. Zhu, S.J. Eichhorn, Carbon nanofibres produced from electrospun cellulose nanofibres, Carbon 58 (2013) 66-75.

19. A.C. Ferrari, J. Robertson, Interpretation of Raman spectra of disordered and amorphous carbon, Phys. Rev. B 61 (2000) 14095-14107.

20. A.C. Ferrari, J. Robertson, Resonant Raman spectroscopy of disordered, amorphous, and diamondlike carbon, Phys. Rev. B 64 (2001) 075414.

21. J.M. Griffin, A.C. Forse, W.Y. Tsai, P.L. Taberna, P. Simon, C.P. Grey, In situ NMR and electrochemical quartz crystal microbalance techniques reveal the structure 
of the electrical doublelayer in supercapacitors, Nat. Mater. 14 (2015) 812-820.

22. A.C. Forse, J.M. Griffin, C. Merlet, P.M. Bayley, H. Wang, P. Simon, C.P. Grey, NMR Study of Ion Dynamics and Charge Storage in Ionic Liquid Supercapacitors J. Am. Chem. Soc. 137 (2015) 7231-7242.

23. L. Borchardt, M. Oschatz, S. Paasch, S. Kaskel, E. Brunner, Interaction of electrolyte molecules with carbon materials of well-defined porosity: characterization by solid-state NMR spectroscopy, Phys. Chem. Chem. Phys. 15 (2013) 15177-15184.

24. T. Kim, K. Ideta, D. Jung, K. Saito, J.-I. Park, C.K. Rhee, J. Miyawaki, I. Mochida, S.-H. Yoon, Quantitative analysis of BF4 ions infiltrated into micropores of activated carbon fibers using nuclear magnetic resonance, RSC Adv. 4 (2014) 16726-16730.

25. J. Hou, C. Cao, F. Idrees, X. Ma, Hierarchical Porous Nitrogen-Doped Carbon Nanosheets Derived from Silk for Ultrahigh-Capacity Battery Anodes and Supercapacitors, ACS Nano 9 (2015) 2556-2564.

26. H. Li, D. Yuan, C. Tang, S. Wang, J. Sun, Z. Li, T. Tang, F. Wang, H. Gong, C. He, Lignin-derived interconnected hierarchical porous carbon monolith with large areal/volumetric capacitances for supercapacitor, Carbon 100 (2016) 151-157.

27. L. Xie, G. Sun, F. Su, X. Guo, Q. Kong, X. Li, X. Huang, L. Wan, W. song, K. Li, C. Lv, C.-M. Chen, Hierarchical porous carbon microtubes derived from willow catkins for supercapacitor applications, J. Mater. Chem. A 4 (2016) 1637-1646.

28. Y.-Q. Zhao, M. Lu, P.-Y. Tao, Y.-J. Zhang, X.-T. Gong, Z. Yang, G.-Q. Zhang, H.-L. Li, Hierarchically porous and heteroatom doped carbon derived from tobacco rods for supercapacitors, J. Power Sources 307 (2016) 391-400.

29. Y. Li, G. Wang, T. Wei, Z. Fan, P. Yan, Nitrogen and sulfur co-doped porous carbon nanosheets derived from willow catkin for supercapacitors, Nano Energy 19 (2016) 165-175.

30. M. Sevilla, W. Gu, C. Falco, M.M. Titirici, A.B. Fuertes, G. Yushin, Hydrothermal synthesis of microalgae-derived microporous carbons for electrochemical capacitors J. Power Sources 267 (2014) 26-32.

31. I.I. Misnon, R.A. Aziz, N.K.M. Zain, B. Vidhyadharan, S.G. Krishnan, R. Jose, 
High performance $\mathrm{MnO}_{2}$ nanoflower electrode and the relationship between solvated ion size and specific capacitance in highly conductive electrolytes, Mater. Res. Bull. 57 (2014) 221-230.

32. D. Aurbach, M.D. Levi, G. Salitra, N. Levy, E. Pollak, J. Muthu, Cation trapping in highly porous carbon electrodes for EDLC cells, J. Electrochem. Soc. 155 (2008) A745-A753.

33. S. Fletcher, V.J. Black, I. Kirkpatrick, A universal equivalent circuit for carbon-based supercapacitors, J. Solid State Electrochem. 18 (2014) 1377-1387.

34. Y. Chen, X. Zhang, D. Zhang, P. Yu, Y. Ma, High performance supercapacitors based on reduced graphene oxide in aqueous and ionic liquid electrolytes, Carbon 49 (2011) 573-580.

35. X. Lyu, F. Su, M. Miao, Two-ply yarn supercapacitor based on carbon nanotube/stainless steel core-sheath yarn electrodes and ionic liquid electrolyte, J. Power Sources 307 (2016) 489-495.

36. J. Wang, J. Tang, Y. Xu, B. Ding, Z. Chang, Y. Wang, X. Hao, H.Dou, J.H. Kimd, X. Zhang, Y. Yamauchi, Interface miscibility induced double-capillary carbon nanofibers for flexible electric double layer capacitors, Nano Energy 28 (2016) 232-240.

37. X. Yu, Y. Kang, H.S. Park, Sulfur and phosphorus co-doping of hierarchically porous graphene aerogels for enhancing supercapacitor performance, Carbon 101 (2016) 49-56.

38. X. Wang, H. Zhou, E. Sheridan, J.C. Walmsley, D. Ren, D. Chen, Geometrically confined favourable ion packing for high gravimetric capacitance in carbon-ionic liquid supercapacitors, Energy Environ. Sci. 9 (2016) 232-239.

39. Y. Xu, Z. Lin, X. Zhong, X. Huang, N.O. Weiss, Y. Huang, X. Duan, Holey graphene frameworks for highly efficient capacitive energy storage, Nat. Commun. 5 (2014) 4554.

40. A.B. Fuertes, M. Sevilla, High-surface area carbons from renewable sources with a bimodal micro-mesoporosity for high-performance ionic liquid-based supercapacitors, Carbon 94 (2015) 41-52. 
41. H. Wang, Z. Li, J.K. Tak, C.M.B. Holt, X. Tan, Z. Xu, B.S. Amirkhiz, D. Harfield, A. Anyia, T. Stephenson, D. Mitlin, Supercapacitors based on carbons with tuned porosity derived from paper pulp mill sludge biowaste, Carbon 57 (2013) 317-328.

42. J. Hou, C. Cao, X. Ma, F. Idrees, B. Xu, X. Hao, W. Lin, From Rice Bran to High Energy Density Supercapacitors: A New Route to Control Porous Structure of 3D Carbon, Sci. Rep. 4 (2014) 7260.

43. Y. Luan, L. Wang, S. Guo, B. Jiang, D. Zhao, H. Yan, C. Tian, H. Fu, A hierarchical porous carbon material from a loofah sponge network for high performance supercapacitors, RSC Adv. 5 (2015) 42430-42437.

44. K. Wu, B. Gao, J. Su, X. Pen, X. Zhang, J. Fu, S. Peng, P.K. Chu, Large and porous carbon sheets derived from water hyacinth for high-performance supercapacitors, RSC Adv. 6 (2016) 29996-30003.

45. P. Hao, Z. Zhao, J. Tian, H. Li, Y. Sang, G. Yu, H. Cai, H. Liu, C.P. Wong, A. Umar, Hierarchical porous carbon aerogel derived from bagasse for high performance supercapacitor electrode, Nanoscale 6 (2014) 12120-12129. 


\section{Figures}

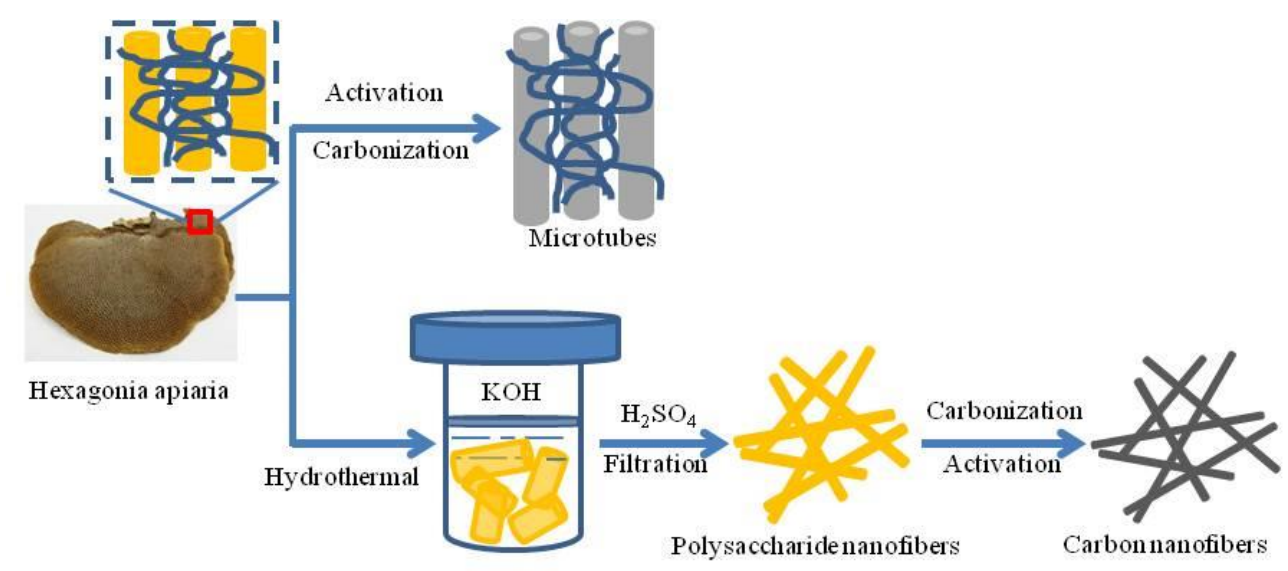

Figure 1. Schematic diagram for the preparation of porous carbons from HA. 

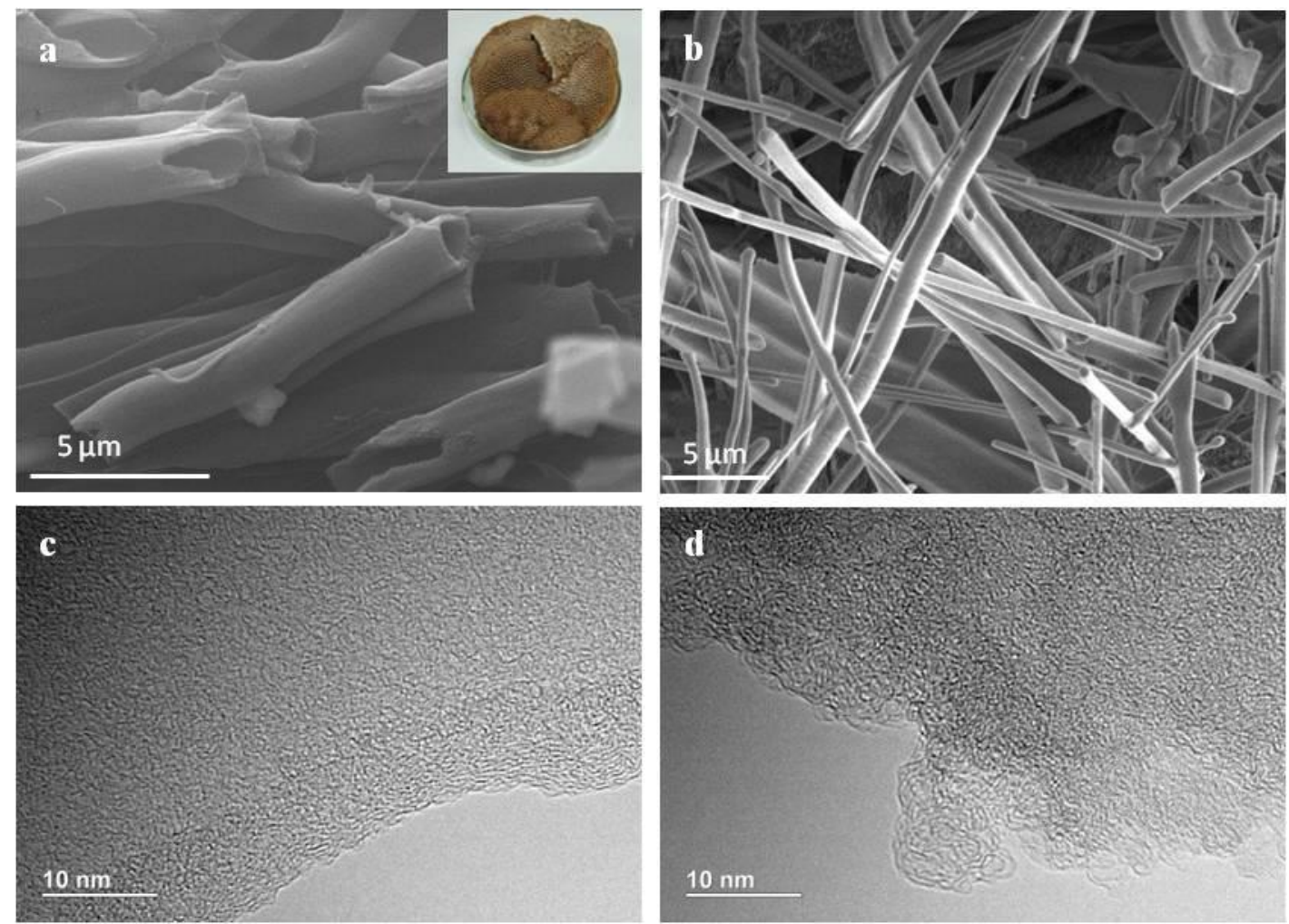

Figure 2. SEM images of: (a) HA-800 and (b) CNF-800. The inset to (a) shows a digital photo of the crude HA. TEM images of: (c) HA-800 and (d) CNF-800. 

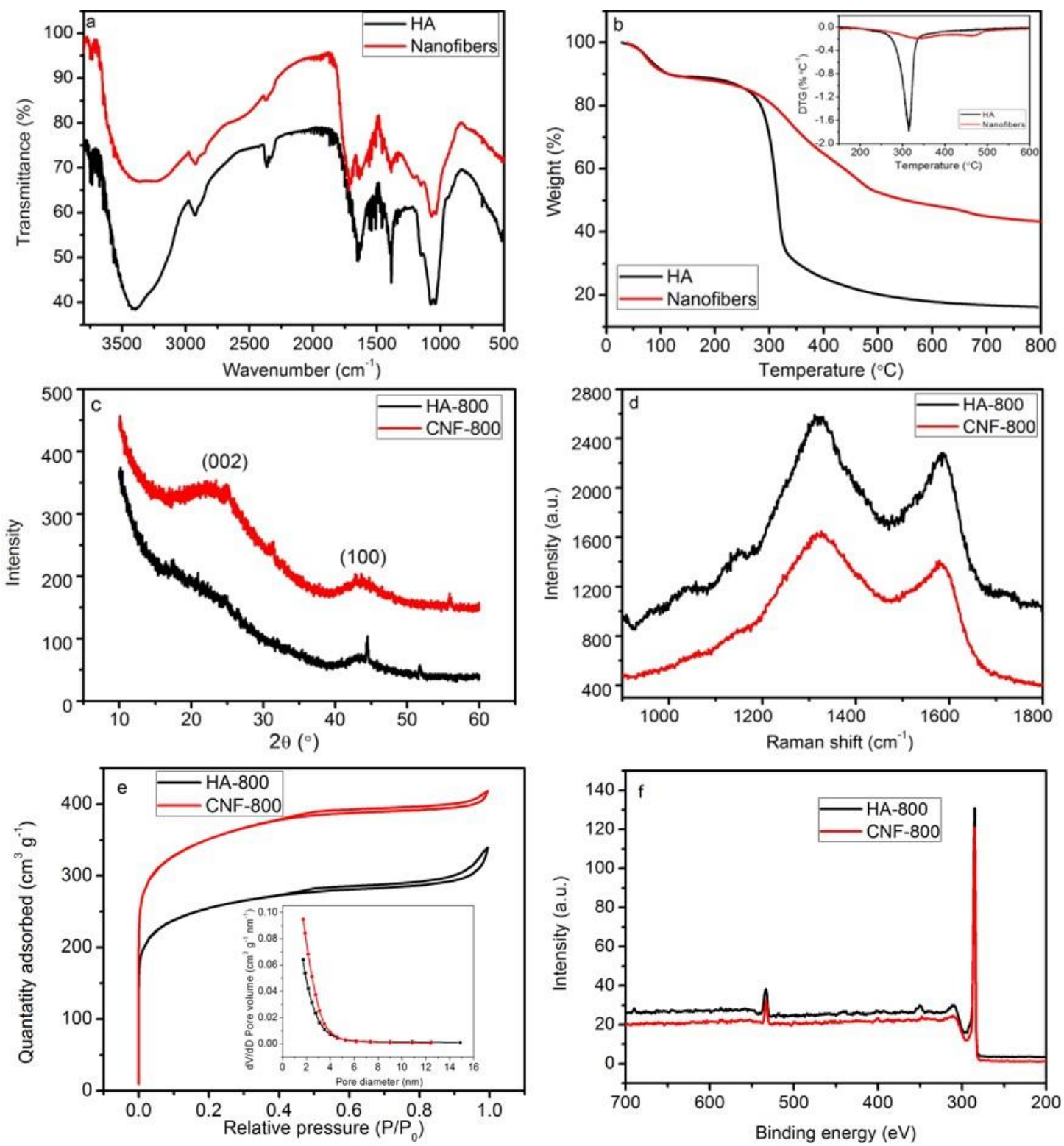

Figure 3. (a) IR spectra, (b) TG and DTG curves for the crude HA and extracted nanofibers, (c) XRD patterns, (d) Raman spectra, (e) $\mathrm{N}_{2}$ adsorption-desorption isothermal cures and (f) XPS spectra for HA-800 and CNF-800. 


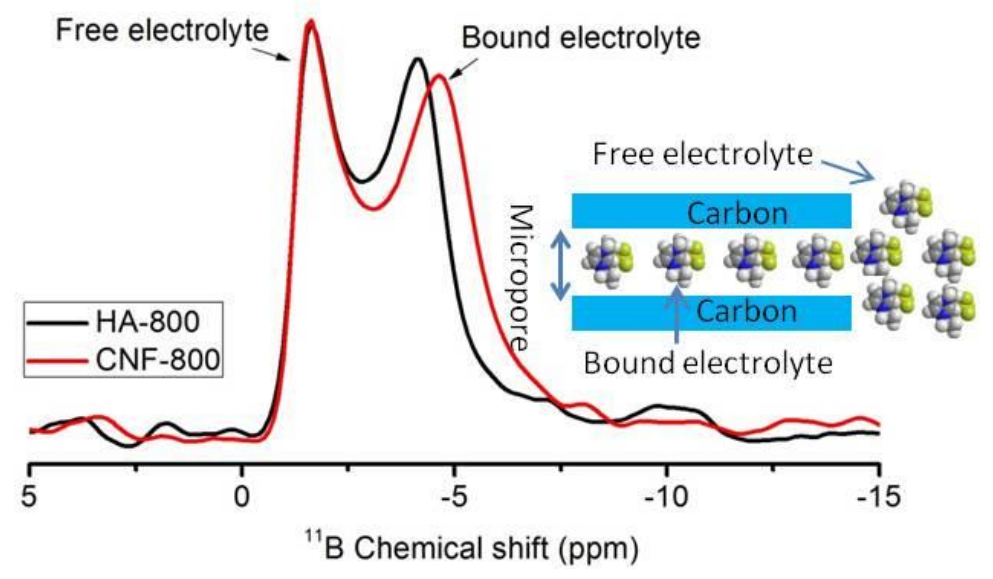

Figure 4. ${ }^{11} \mathrm{~B}$ NMR spectra and a schematic diagram for the porous carbons soaked with $\mathrm{EMIImBF}_{4}$. 

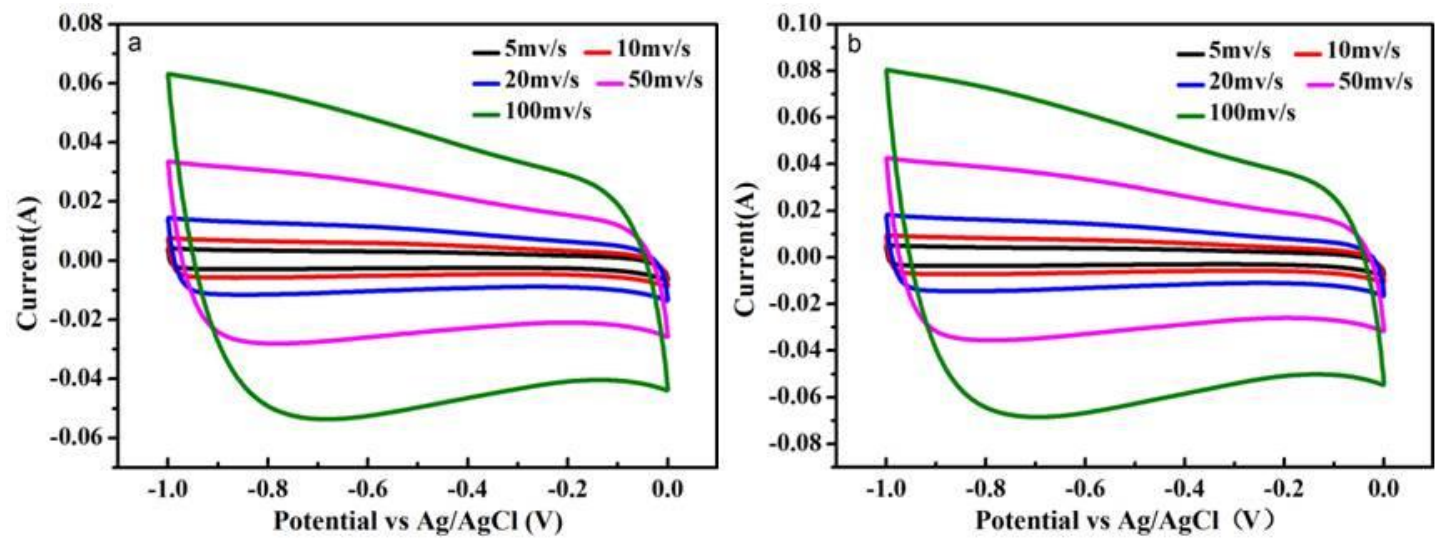

Figure 5. CV curves for the porous carbons measured with a three-electrode configuration in $6 \mathrm{M} \mathrm{KOH}$ electrolyte: (a) HA-800 and (b) CNF-800. The reference electrode was $\mathrm{Ag} / \mathrm{AgCl}$ and the counter electrode was a Pt wire. 

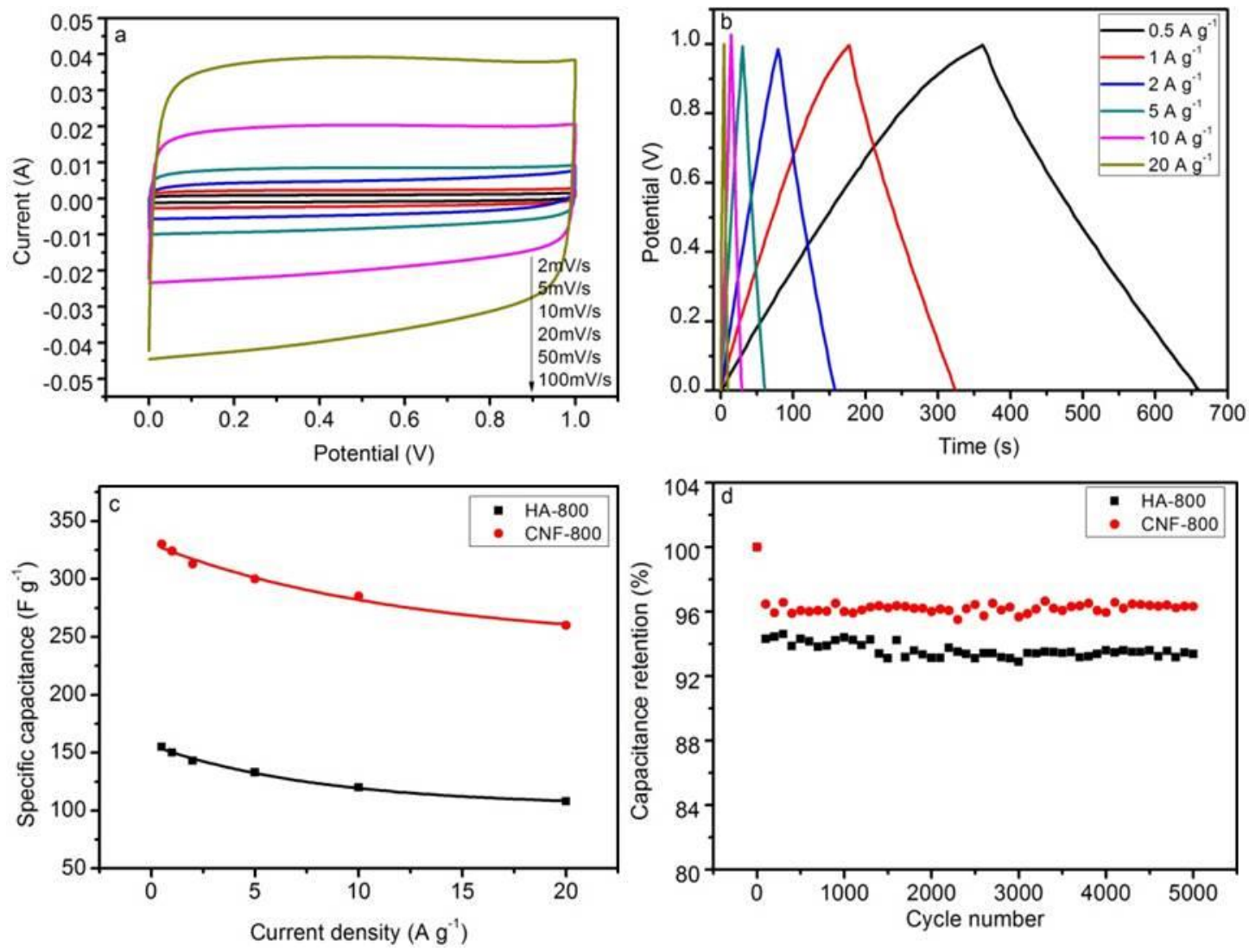

Figure 6. Electrochemical characterization in $6 \mathrm{M} \mathrm{KOH}$ electrolyte: (a) $\mathrm{CV}$ curves and (b) charge/discharge curves for CNF-800 measured at different current densities; (c) the specific capacitance of the electrodes as a function of current density; (d) cyclic performance of the electrodes at a constant current density of $2 \mathrm{~A} \mathrm{~g}^{-1}$. The devices were stabilized for 20 cycles prior to the stability tests. 


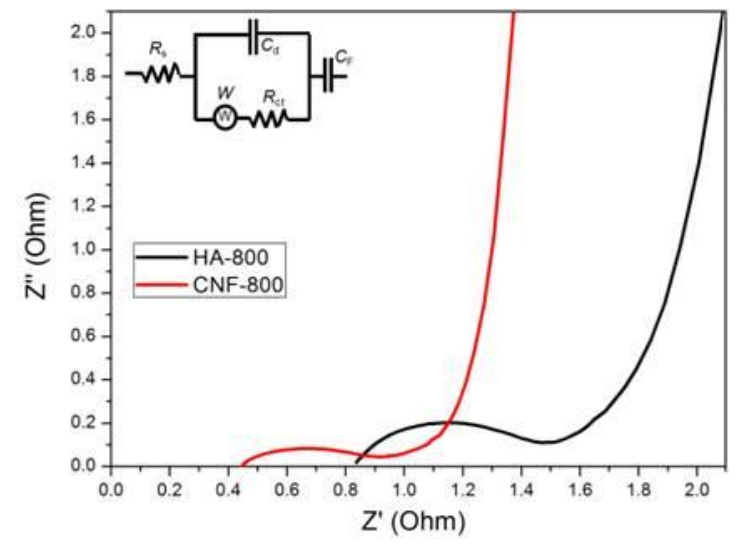

Figure 7. Impedance Nyquist plots of the electrodes. The inset shows the equivalent circuit. 

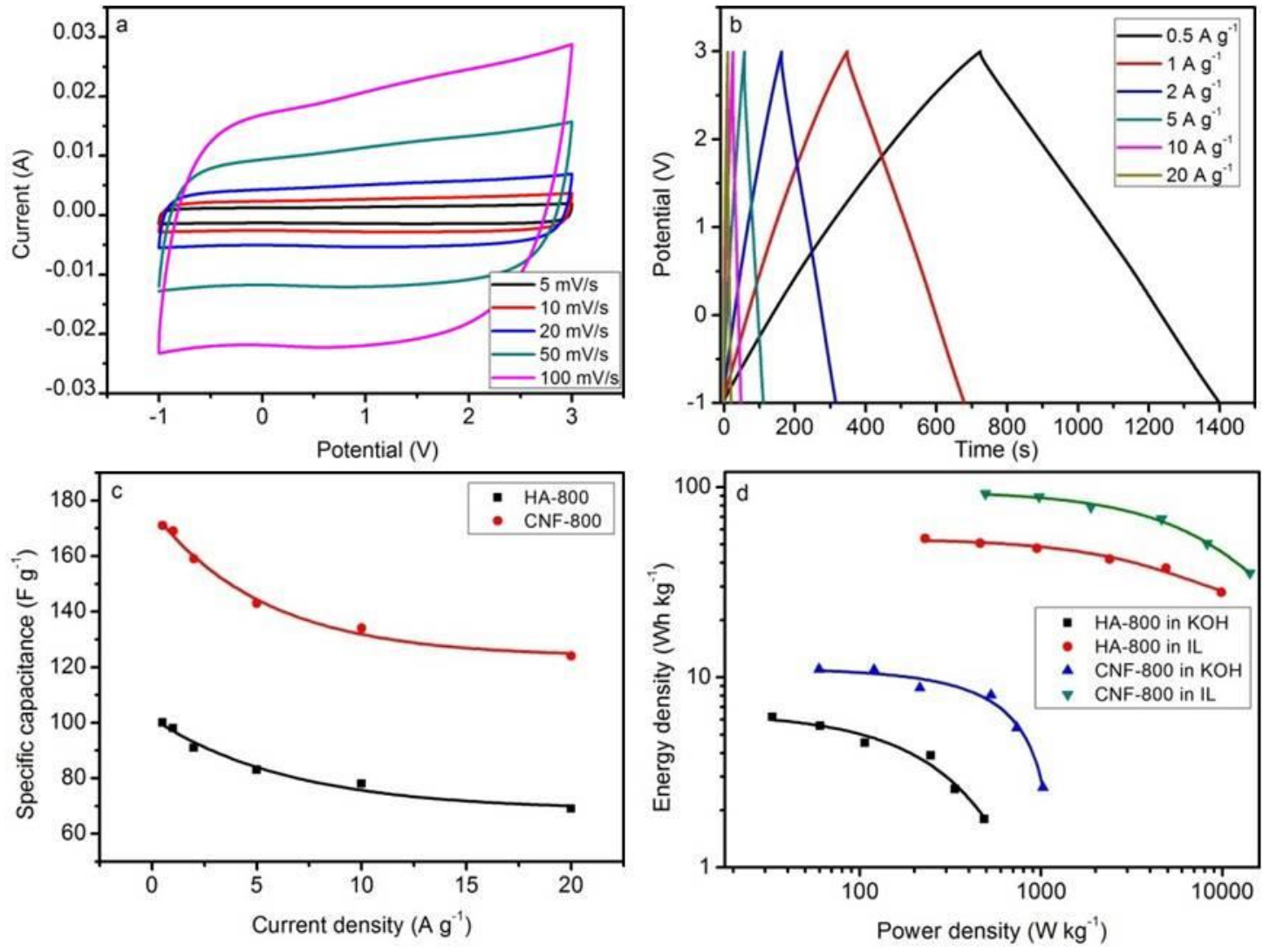

Figure 8. Electrochemical characterization in the IL electrolyte: (a) CV curves and (b) charge/discharge curves for CNF-800 measured at different current densities; (c) the specific capacitance of the electrodes as a function of current density; (d) Ragone plots of the supercapacitors. 
Tables

Table 1 Comparison of capacitive performances of biomass-derived carbons

\begin{tabular}{|c|c|c|c|c|c|}
\hline r & lyte & $\begin{array}{l}\text { Gravimetric } \\
\text { Capacitance } \\
\text { (Testing condition) }\end{array}$ & $\begin{array}{l}\text { Areal } \\
\text { capacitance } \\
\left(\mu \mathrm{F} \mathrm{cm}^{-2}\right)\end{array}$ & $\begin{array}{l}\text { Energy } \\
\text { density (Power } \\
\text { density) }\end{array}$ & Ref. \\
\hline $\begin{array}{l}\text { Willow } \\
\text { catkin }\end{array}$ & $\mathrm{KOH}$ & $\begin{array}{l}298 \mathrm{~F} \mathrm{~g}^{-1}(0.5 \mathrm{~A} \\
\left.\mathrm{g}^{-1}\right)\end{array}$ & 15.4 & $\begin{array}{l}21 \mathrm{Wh} \mathrm{kg}^{-1} \\
\left(180 \mathrm{~W} \mathrm{~kg}^{-1} \text { in }\right. \\
\left.\mathrm{Na}_{2} \mathrm{SO}_{4}\right)\end{array}$ & [29] \\
\hline $\begin{array}{l}\text { Loofah } \\
\text { sponge }\end{array}$ & $\mathrm{KOH}$ & $\begin{array}{l}304 \mathrm{~F} \mathrm{~g}^{-1}(1 \mathrm{~A} \\
\left.\mathrm{g}^{-1}\right)\end{array}$ & 17.5 & $\begin{array}{l}10 \mathrm{Wh} \mathrm{kg}^{-1} \\
\left(500 \mathrm{~W} \mathrm{~kg}^{-1}\right)\end{array}$ & [43] \\
\hline $\begin{array}{l}\text { Water } \\
\text { hyacinth }\end{array}$ & $\mathrm{KOH}$ & $\begin{array}{l}273 \mathrm{~F}^{-1}(1 \mathrm{~A} \\
\left.\mathrm{g}^{-1}\right)\end{array}$ & 20.9 & $\begin{array}{l}7.24 \quad \mathrm{Wh} \\
\mathrm{kg}^{-1}\left(1 \mathrm{Ag}^{-1}\right)\end{array}$ & [44] \\
\hline $\begin{array}{l}\text { Sugarca } \\
\text { ne } \\
\text { bagasse }\end{array}$ & $\mathrm{KOH}$ & $\begin{array}{l}142.1 \mathrm{~F} \mathrm{~g}^{-1}(0.5 \\
\left.\mathrm{A} \mathrm{g}^{-1}\right)\end{array}$ & 7.5 & $\begin{array}{l}19.74 \quad \mathrm{Wh} \\
\mathrm{kg}^{-1}(500 \quad \mathrm{~W} \\
\left.\mathrm{kg}^{-1}\right)\end{array}$ & [45] \\
\hline $\begin{array}{l}\text { HA- } \\
\text { extracte } \\
\text { d } \\
\text { nanofibers }\end{array}$ & $\mathrm{KOH}$ & $\begin{array}{l}324 \mathrm{~F}^{-1} \quad(1 \mathrm{~A} \\
\left.\mathrm{g}^{-1}\right)\end{array}$ & 25.3 & $\begin{array}{l}11 \mathrm{Wh} \mathrm{kg}^{-1} \\
\left(60 \mathrm{~W} \mathrm{~kg}^{-1}\right)\end{array}$ & $\begin{array}{l}\text { This } \\
\text { work }\end{array}$ \\
\hline $\begin{array}{l}\text { Hemp } \\
\text { bast fiber }\end{array}$ & IL & $\begin{array}{l}122 \quad F^{-1} \quad(1 \quad A \\
\left.g^{-1}\right)\end{array}$ & 5.3 & $\begin{array}{l}19 \mathrm{Wh} \mathrm{kg}^{-1} \\
\left(20 \mathrm{~kW} \mathrm{~kg}^{-1}\right)\end{array}$ & [4] \\
\hline
\end{tabular}




\begin{tabular}{|c|c|c|c|c|c|}
\hline $\begin{array}{l}\text { Wood } \\
\text { sawdust }\end{array}$ & IL & $\begin{array}{l}170 \mathrm{~F}^{-1} \quad(1 \mathrm{~A} \\
\left.\mathrm{g}^{-1}\right)\end{array}$ & 5.0 & $\begin{array}{l}20 \mathrm{Wh} \mathrm{kg}^{-1} \\
\left(42 \mathrm{~kW} \mathrm{~kg}^{-1}\right)\end{array}$ & [40] \\
\hline $\begin{array}{l}\text { Rice } \\
\text { bran }\end{array}$ & IL & $\begin{array}{l}196 \mathrm{~F} \mathrm{~g}^{-1}(1 \mathrm{~A} \\
\left.\mathrm{g}^{-1}\right)\end{array}$ & 7.9 & $\begin{array}{r}91.4 \quad \mathrm{Wh} \\
\mathrm{kg}^{-1}\left(0.1 \mathrm{~A} \mathrm{~g}^{-1}\right)\end{array}$ & [42] \\
\hline $\begin{array}{l}\text { Paper } \\
\text { pulp mill } \\
\text { biowaste }\end{array}$ & IL & N/A & N/A & $\begin{array}{l}51 \mathrm{Wh} \mathrm{kg}^{-1} \\
\left(375 \mathrm{~W} \mathrm{~kg}^{-1}\right)\end{array}$ & [41] \\
\hline $\begin{array}{l}\text { HA-ext } \\
\text { racted } \\
\text { nanofibers }\end{array}$ & IL & $\begin{array}{l}171 \quad F \quad g^{-1}(1 \quad A \\
\left.g^{-1}\right)\end{array}$ & 13.4 & $\begin{array}{l}92.3 \quad \text { Wh } \\
\mathrm{kg}^{-1} \quad(493 \quad \mathrm{~W} \\
\left.\mathrm{kg}^{-1}\right)\end{array}$ & $\begin{array}{r}\text { This } \\
\text { work }\end{array}$ \\
\hline
\end{tabular}

